\title{
ACESSO E PERMANÊNCIA DE ESTUDANTES COM DEFICIÊNCIA NO ENSINO SUPERIOR: APONTAMENTOS DE PESQUISA
}

\author{
ACCESS AND STAY OF STUDENTS WITH DISABILITIES IN HIGHER \\ EDUCATION: RESEARCH NOTES
}

Izane Flexa Santa Brigida ${ }^{42}$

Carolline Septimio Limeira ${ }^{43}$

\begin{abstract}
Resumo
Garantir o acesso de estudantes com deficiência ao ensino superior deve ser premissa de qualquer projeto educacional que se pense inclusivo. Partindo desse princípio, o presente artigo surge a partir dos estudos no âmbito da Iniciação Científica, tendo por objetivo analisar pesquisas que abordam a temática da acessibilidade de estudantes no ensino superior. Metodologicamente, optamos por um estudo qualitativo dos trabalhos apresentados nas últimas cinco reuniões nacionais da Associação Nacional de PósGraduação e Pesquisa em Educação(ANPED). Desse modo desejamos conhecer o que os estudos mais recentes nos mostram no campo da educação inclusiva nesse nível de ensino. Para o debate acerca da acessibilidade no ensino superior utilizou-se como referencial teórico Skliar (2012; 2013), Rodrigues (2006) Sassaki (2010) e Lopes (2017). $\mathrm{Na}$ análise de dados foram levantadas questões sobre o ingresso e permanência desses acadêmicos. Tendo em vista a importância das instituições de ensino superior para a eliminação/minimização das barreiras na estrutura física e social na trajetória da vida universitária, a pesquisa demonstrou que as melhorias promovidas pela acessibilidade contribuem diretamente para o aumento de matrículas de estudantes com deficiência no ensino superior e que esses benefícios cooperam para a permanência dos acadêmicos nessas instituições.
\end{abstract}

Palavras-chave: Inclusão. Acessibilidade. Ensino Superior. Estudantes com deficiência.

\begin{abstract}
Ensuring access for students with disabilities to higher education must be the premise of any educational project that is thought to be inclusive. Based on this principle, this article aimed to analyze research that addresses the issue of student accessibility in higher education. Methodologically, we opted for a qualitative study of the works presented in the last five national meetings of the National Association of Graduate

\footnotetext{
42 Graduanda em Pedagogia pela Faculdade Estácio Castanhal (FCAT). Email: izane.flexa@yahoo.com.br . ORCID: 0000-0002-9609-3621

43 Doutora em Educação pela UDESC; graduada em Pedagogia pela UEPA. Coordenadora do Curso de Pedagogia e NAAP (Núcleo de Atendimento e Apoio Psicopedagógico) da Faculdade Estácio Castanhal (FCAT). Email: carolline.limeira@estacio.br. ORCID: 0000-0003-2669-3119
} 


\section{RevistAleph}

Studies and Research in Education - (ANPED). For the debate on accessibility in higher education, Skliar (2012; 2013), Rodrigues (2006) Sassaki (2010) and Lopes (2017) were used as the theoretical framework. In the data analysis, questions were raised about the admission and permanence of these students. In view of the importance of higher education institutions for the elimination / minimization of barriers in the physical and social structure in the trajectory of university life, the research demonstrated that the improvements promoted by accessibility directly contribute to the increase in enrollment of students with disabilities in teaching and that these benefits cooperate for the permanence of academics in these institutions.

Keywords: Inclusion. Accessibility. University education. Disabled students.

\section{Introdução}

\section{Notas do contexto histórico}

Historicamente, o lugar da pessoa com deficiência sempre foi marcado pela exclusão e discriminação. Consideradas anomalias sociais, essas pessoas eram tratadas como indivíduos a serem eliminados, uma vez que não seguiam padrões estéticos e de comportamento em consonância com as normas sociais. Skliar (2013) nos lembra que somente na Idade Média foram considerados dignos de sobrevivência, contudo, ainda eram tratados como aberrações que necessitavam de salvação para suas almas pecaminosas.

Do extermínio à sobrevivência, a pessoa com deficiência passa a pertencer à sociedade, ainda que sofrendo preconceitos e estereótipos. Nesse sentido de sentença biológica surge o discurso da medicina e se torna um aliado na concepção clínica da Educação Especial. Segundo Skliar (2013), os questionamentos implícitos nessa concepção seriam os seguintes:

\footnotetext{
Quando se tira ou se reduz o tamanho da deficiência? Quando se eliminam ou se reduzem as consequências sociais? O homem seria homem se não fosse surdo? Se não fosse cego, se não fosse retardado mental, se não fosse negro, se não fosse homossexual, se não fosse fanático religioso, se não fosse indígena? (SKLIAR, 2013 p. 9).
}

Não há relação alguma entre a deficiência e seus supostos derivados sociais diretos. Obviamente que duas pessoas com idênticas deficiências e que vivem em 


\section{RevistAleph}

sociedades diferentes possuem trajetórias de desenvolvimento diferente, portanto, há que se observar muito além do corpo lesionado, do laudo médico que determina a limitação.

Para Sassaki (2010), os problemas da atualidade ligados à pessoa com deficiência não estão na deficiência em si, mas nas estruturas sociais que não estão aptas a recebê-las em igualdade de oportunidades. Acerca dessa ideia, chamada modelo social de deficiência, esclarece-nos Diniz (2012)

Ser cego é apenas uma das muitas formas corporais de estar no mundo. Mas, como qualquer estilo de vida, um cego necessita de condições sociais favoráveis para levar adiante seu modo de viver a vida. A deficiência visual não significa isolamento ou sofrimento, pois não há sentença biológica de fracasso por alguém não enxergar. O que existe são contextos sociais pouco sensíveis à compreensão da diversidade corporal como diferentes estilos de vida (DINIZ, 2012, p. 8).

Vale destacar o conceito de pessoas com deficiência previsto no Decreto 6.949 (2009) que promulga a Convenção Internacional sobre os Direitos das Pessoas com Deficiência e seu Protocolo Facultativo, assinados em Nova York, em 30 de março de 2007 no Art. 1은

São aquelas que têm impedimentos de longo prazo de natureza física, mental, intelectual ou sensorial, os quais, em interação com diversas barreiras, podem obstruir sua participação plena e efetiva na sociedade em igualdades de condições com as demais pessoas (BRASIL, 2009).

Pensar em acesso e inclusão perpassa por considerarmos toda e qualquer forma de existir e produzir conhecimentos. O pleno desenvolvimento do ser humano é um dos princípios da educação, em consonância às condições de acesso e permanência nos espaços educacionais. Nos últimos anos, o perfil dos estudantes que ingressam no nível superior vem mudando. A entrada de estudantes com deficiência nas universidades, faculdades e institutos de educação é fruto, principalmente, de um longo processo de transformação social produzido por meio de movimentos sociais, econômicos e culturais erigidos na modernidade. 


\title{
RevistAleph
}

Em virtude de tais aspectos, as universidades têm buscado atender às adequações físicas e pedagógicas que são definidas em parâmetros legais. Sobre a inclusão educacional, a Lei Brasileira de Inclusão- (LBI) em seu Art. 27 declara que

\begin{abstract}
A educação constitui direito da pessoa com deficiência, assegurado sistema educacional inclusivo em todos os níveis e aprendizado ao longo de toda a vida, de forma a alcançar o máximo desenvolvimento possível de seus talentos e habilidades físicas, sensoriais, intelectuais e sociais, segundo suas características, interesses e necessidades de aprendizagem (BRASIL, 2015).
\end{abstract}

Diante da problemática observada nesse contexto, debruçamo-nos sobre o tema da acessibilidade, tendo como caminho da pesquisa a análise sobre quem é esse estudante e como é recebido no ensino superior na perspectiva de acesso, inclusão e permanência. Essa pesquisa surge a partir dos estudos no âmbito da Iniciação científica que pesquisa tal temática. Para esse objetivo, analisamos as últimas produções científicas na temática conjuntamente aos dispositivos legais que versam sobre a inclusão educacional. Conhecermos as investigações recentes no campo de pesquisa que aborda a temática é fundamental para a ancoragem de outras pesquisas e fortalecimento do campo de estudos. O artigo justifica-se pela necessidade de trabalharmos o tema da inclusão no ensino superior, porque acreditamos ser esta pesquisa uma ferramenta essencial para o debate da acessibilidade nos ambientes a que esses estudantes têm o direito de permanência e usabilidade com segurança e autonomia.

\section{Metodologia}

Com base em uma metodologia de estudos exploratórios (TRIVINÕS, 2011) buscou-se delinear um mapeamento bibliográfico por meio de consulta às produções no Grupo de Trabalho- (GT) em Educação Especial (GT-15) da Associação Nacional de Pós-Graduação e Pesquisa em Educação- (ANPED). O marco temporal de análise das produções publicadas envolve o intervalo de 2012 a 2019. Para localizarmos as publicações, fizemos uso das palavras-chaves: "inclusão", "ensino superior", 


\section{RevistAleph}

"acessibilidade" e "estudante com deficiência". Inicialmente optamos por mapear os trabalhos na categoria "aceitos" nas reuniões nacionais. Nesse momento obtivemos uma inexpressiva quantidade de pesquisas acadêmicas, no que se refere a essa temática. Por conseguinte, acabamos considerando as publicações na categoria "excedente" tendo em vista a melhoria de nossa análise. O total de 5 artigos foram encontrados, sendo 3 na categoria "aceitos" e 2 na categoria "excedente". Na análise dos artigos mencionamos as nomenclaturas utilizadas pelos autores pela fidelidade aos termos usados nas publicações.

\section{Das publicações: achados de inclusão}

Nosso enfoque envolveu a leitura minuciosa dos trabalhos publicados sobre a inclusão no ensino superior. Todas as pesquisas derivam de instituições públicas e têm em como foco os estudantes com deficiências, com ênfase na surdez, cegueira e baixa visão. $O$ objetivo de analisarmos as pesquisas realizadas nas últimas 5 reuniões nacionais da ANPED relacionam-se ao interesse de identificarmos o que está sendo investigado no campo da inclusão no ensino superior na atualidade.

Com relação à posição geográfica de publicações por região brasileira, apenas 2\% do total de trabalhos do GT-15 são advindos da região Norte nas últimas reuniões nacionais. Esses dados nos mostram a carência de estudos sobre a temática e a necessidade de mais pesquisas relacionadas ao assunto nos seus diversos aspectos.

O resultado do levantamento das produções apontou a presença de alguns temas mais trabalhados, tais como, inclusão na educação superior, estudantes com deficiência: cegos e surdos universitários, superação e mediação pedagógica. Os artigos mapeados foram tabulados e descritos a partir dos seguintes apontamentos: título, autor (a), ano de publicação, instituição e resultados das pesquisas, podendo ser observados de acordo com a tabela a seguir. 


\section{RevistAleph}

TABELA 01- Trabalhos apresentados nas últimas cinco Reuniões Científicas Nacionais da ANPED

\begin{tabular}{|c|c|c|c|c|}
\hline TíTULO & AUTO(RES) & ANO & INSTITUIÇÃO & RESULTADOS \\
\hline $\begin{array}{l}\text { ROMPENDO A } \\
\text { INVISIBILIDADE } \\
\text { SOCIAL DE PESSOAS } \\
\text { COM DEFICIÊNCIA: A } \\
\text { HISTÓRIA DE VIDA DE } \\
\text { UMA UNIVERSITÁRIA } \\
\text { QUE EXERCE A } \\
\text { AUTOADVOCACIA }\end{array}$ & $\begin{array}{l}\text { Taísa Caldas } \\
\text { Dantas }\end{array}$ & 2012 & UFPB & $\begin{array}{l}\text { Os achados da pesquisa } \\
\text { revelam que esta jovem se } \\
\text { empoderou por meio das } \\
\text { diversas oportunidades a que } \\
\text { foi exposta e hoje exerce a } \\
\text { autoadvocacia, a qual é } \\
\text { revelada nos seguintes } \\
\text { componentes presentes em } \\
\text { sua vida: consciência do valor } \\
\text { que possui enquanto ser } \\
\text { humano; inserção em várias } \\
\text { esferas sociais; conhecimento } \\
\text { acerca dos seus direitos e } \\
\text { deveres; engajamento em } \\
\text { grupo que adere e propaga a } \\
\text { filosofia da autoadvocacia. }\end{array}$ \\
\hline 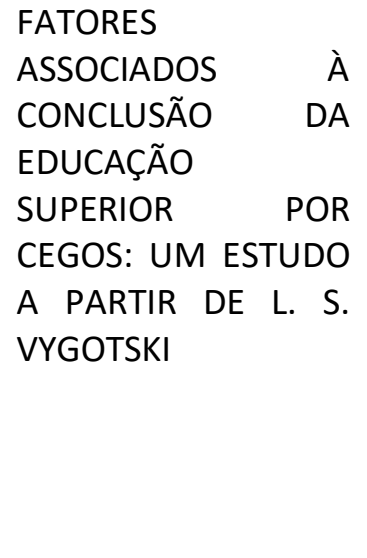 & $\begin{array}{l}\text { Bento Selau } \\
\text { Magda } \\
\text { Floriana } \\
\text { Damiani }\end{array}$ & 2013 & $\begin{array}{l}\text { UNIPAMPA, } \\
\text { UFPel }\end{array}$ & $\begin{array}{l}\text { Os resultados indicaram que } \\
\text { as dificuldades encontradas } \\
\text { durante a educação superior } \\
\text { interferiram no percurso dos } \\
\text { sujeitos nesse nível de } \\
\text { educação. Os principais } \\
\text { fatores identificados nos } \\
\text { dados e interpretados com } \\
\text { apoio nos estudos de } \\
\text { Vygotski foram internos: a } \\
\text { tomada de consciência e a } \\
\text { vontade. }\end{array}$ \\
\hline $\begin{array}{lr}\text { GENEALOGIA } & \text { DA } \\
\text { IDEIA } & \text { DE } \\
\text { SUPERAÇÃO } & \text { POR } \\
\text { CEGOS: UM ESTUDO } \\
\text { COM BASE } & \text { EM } \\
\text { VYGOTSKI } & \end{array}$ & Bento Selau & 2015 & UNIPAMPA & $\begin{array}{l}\text { Os resultados apontam que o } \\
\text { conceito de superação } \\
\text { dialética da cegueira } \\
\text { proposto por Vygotski com } \\
\text { base em Hegel volta-se para } \\
\text { elevação do cego, por } \\
\text { intermédio dos instrumentos } \\
\text { culturais de mediação. Para } \\
\text { os participantes da } \\
\text { investigação, o interesse no } \\
\text { aprendizado dos conceitos } \\
\text { científicos foi o grande aliado }\end{array}$ \\
\hline
\end{tabular}




\section{RevistAleph}

\begin{tabular}{|c|c|c|c|c|}
\hline & & & & $\begin{array}{l}\text { para a superação dialética da } \\
\text { cegueira. }\end{array}$ \\
\hline $\begin{array}{l}\text { REPRESENTAÇÕES } \\
\text { ACERCA DOS } \\
\text { PROJETOS DE VIDA } \\
\text { DE SURDOS } \\
\text { UNIVERSITÁRIOS }\end{array}$ & $\begin{array}{l}\text { Arlete } \\
\text { Marinho } \\
\text { Gonçalves }\end{array}$ & 2017 & UFPA & $\begin{array}{l}\text { Os resultados apontam que } \\
\text { as Representações Sociais } \\
\text { sobre os projetos de vida dos } \\
\text { surdos universitários } \\
\text { assinalam relações advindas } \\
\text { com seus processos de } \\
\text { escolarização, com a família e } \\
\text { com a falta de acessibilidade, } \\
\text { muitas delas apontadas pelas } \\
\text { situações de exclusão, } \\
\text { vivenciadas nesses espaços. }\end{array}$ \\
\hline $\begin{array}{lr}\text { RELAÇÃO } & \\
\text { PEDAGÓGICA } & \text { NA } \\
\text { RELAÇÃO } & \text { COM } \\
\text { ESTUDANTES } & \text { COM } \\
\text { DEFICIÊNCIA } & \text { NA } \\
\text { EDUCAÇÃO } & \\
\text { SUPERIOR } & \end{array}$ & $\begin{array}{l}\text { Tania Mara } \\
\text { Zancanaro } \\
\text { Pieczkowski }\end{array}$ & 2017 & $\begin{array}{l}\text { UNOCHAPEC } \\
\text { Ó }\end{array}$ & $\begin{array}{l}\text { O estudo aponta que os } \\
\text { professores são subjetivados } \\
\text { pelos discursos da inclusão, } \\
\text { verdade inquestionável em } \\
\text { nossos tempos, o que resulta } \\
\text { em posturas amorosas e } \\
\text { solidárias. }\end{array}$ \\
\hline
\end{tabular}

Fonte: Elaboração própria. 2020.

\section{Resultados e discussões}

\section{O ingresso}

No artigo de Gonçalves (2017) intitulado “Representações acerca dos projetos de vida de Surdos Universitários", que diz respeito ao ingresso no ensino superior, as narrativas apontam que os acadêmicos ingressaram por meio de sistemas de cotas para estudantes com deficiência. Tal sistema consiste na Lei de Cotas, um instrumento criado para contemplar os estudantes de escolas públicas, de baixa renda, negros, pardos, indígenas e pessoas com deficiência, a fim de auxiliar o ingresso ao ensino superior. Nesse sentido, ressaltamos a importância das políticas afirmativas no processo de inclusão como forma de acesso desses estudantes a esse nível da educação formal. 


\section{RevistAleph}

Nessa seara, Cabral (2018, p. 23) nos leva a refletir dizendo que, no âmbito das políticas de ações afirmativas, o processo de incorporação da diversidade sociocultural deve ser acompanhado por uma política cultural de reconhecimento do outro e de interação entre os sujeitos, com vistas a superar as resistências de uma histórica hegemonia do corpo social, do status quo universitário.

A Lei no 13.409 de 28 de dezembro de 2016, dispõe sobre a reserva de vagas para pessoas com deficiência nos cursos técnico de nível médio e superior das instituições federais de ensino. A Lei expressa que

Em cada instituição federal de ensino superior, as vagas de que trata o art. 10 desta Lei serão preenchidas, por curso e turno, por autodeclarados pretos, pardos e indígenas e por pessoas com deficiência, nos termos da legislação, em proporção ao total de vagas no mínimo igual à proporção respectiva de pretos, pardos, indígenas e pessoas com deficiência na população da unidade da Federação onde está instalada a instituição, segundo o último censo da Fundação Instituto Brasileiro de Geografia e Estatística - IBGE. (BRASIL, 2016)

Skliar (2013) esclarece que é preciso evidenciar as fronteiras e colocar no debate a inclusão efetivamente para que o acesso não possa ser interpretado como ideia de integração. Ainda nesse debate, Rodrigues (2004) destaca que o acesso não está resolvido pela implementação da reserva de vagas; antes, esse deve ser um item permanente de luta. Entendemos por acesso, no âmbito que agora tratamos, o conjunto de possibilidades específicas que permitem ao estudante com deficiência frequentar e relacionar-se com a comunidade acadêmica.

Selau e Damiani (2013) no artigo intitulado "Fatores associados à conclusão da educação superior por cegos: um estudo a partir de L.S. Vygotski" apontam o ingresso e a permanência como dois aspectos básicos que devem ser observados por gestores e professores. Exemplificando a falta de acessibilidade existente no ensino superior, apresentam o processo seletivo para ingresso no ensino superior realizado para cegos. Para os pesquisadores, há necessidade de reestruturação desse formato para que se torne adequadamente um processo inclusivo.

No tocante às barreiras para ingresso de estudantes cegos no ensino superior, Selau e Damiani (2013) destacam: a falta de material impresso em braille e a realização 


\section{RevistAleph}

da prova com apoio de um leitor, que, não raro, está mal preparado para a tarefa. Essas dificuldades são vistas como um dos problemas logo na tentativa de ingresso e esses entraves acompanham os estudantes comprometendo a produção acadêmica. São denunciados ainda problemas de organização das instituições de ensino superior, especialmente representadas pela ausência de políticas efetivas de inclusão.

Nos estudos de Pieczkowski (2017) no artigo intitulado "Mediação Pedagógica na relação com Estudantes com Deficiência na Educação Superior", a autora nos diz que esses encontros com os estudantes com deficiência são frequentemente narrados pelos docentes como "sujeitos com problemas e causadores de problemas". Quando se coloca a deficiência como ponto de partida na relação com o sujeito, faz-se erroneamente, por desconsiderar o ser social, capaz de aprender e ensinar, pois "Quando passamos a reconhecer alguém pelo rótulo, o relacionamento passa a ser com este, e não com o indivíduo" (SILVA, 2006, p. 427).

Pensar na pessoa com deficiência remete ao empecilho, dificuldade, barreiras, e essa visão relaciona-se à produção cultural da deficiência que é fruto da idealização do sujeito padronizado que norteia os processos educativos. O sistema educacional não se prepara para acolher esses estudantes com limitações. Articulações no sentido de lidar com os estudantes acontecem somente quando adentram as instituições e surge então o que Morin (2011) descreve como Inesperado:

É que nos instalamos de maneira segura em nossas teorias e ideias, e estas não têm estrutura para acolher o novo. Entretanto, o novo brota sem parar. Não podemos jamais prever como se apresentará. E quando o inesperado se manifesta, é preciso sermos capazes de rever nossas teorias e ideias, em vez de deixar o fato novo entrar à força na teoria incapaz de recebê-lo (MORIN, 2011, p. 29).

Nota-se, portanto, que as barreiras são comumente experienciadas pelos estudantes causando desconforto no contato com os docentes. Tal incômodo coloca em evidência a necessária desconstrução do saber docente. A predominância da palavra "superação" vinda dos estudantes com deficiência demonstra nos estudos algo aliado a sobreviver, a uma atitude individual de esforço diante das barreiras físicas e sociais observadas diante das falas dos colegas e professores. 


\section{RevistAleph}

A frequente cobrança, implícita, denota no dia-a-dia que esses estudantes têm que demonstrar serem capazes de realizar suas tarefas, demonstrar que são capazes o suficiente de ocupar o espaço que não Ihes pertence. Em muitas narrativas descrevem que são cobrados duas vezes mais que os colegas que não possuem deficiência. Na história dessa população, poucas são as experiências de sucesso conhecidas no campo da educação, da vida afetiva e do mercado de trabalho. Quando se trata de pessoas com deficiência, isto ocorre porque a ênfase recai sobre a patologia, o diagnóstico e a respectiva limitação, condição que torna invisível suas potencialidades como são conhecidas por qualquer outro ser humano (GLAT, 2004).

Quando os estudos contextualizam a vida desses estudantes é notório o processo de enfrentamento das barreiras em várias dimensões de suas vidas e, nesse sentido, a superação tem um significado peculiar. A pesquisa de Selau (2015) no artigo "Genealogia da ideia de superação por cegos: um estudo com base em Vygotski" diz que há um entendimento errôneo sobre a palavra (inclusive como considerada pelos sujeitos da pesquisa) que remetem a ideias popularmente conhecidas ou mitos. Esse estudo nos diz que a superação não deve estar centrada no sujeito pelo esforço pessoal, mas num conjunto de estratégias no planejamento, na implementação e na avaliação feita por professores, gestores e demais envolvidos no processo, capazes de divulgar as potencialidades dos sujeitos sem responsabilizá-los ou atribuir somente a eles o mérito de uma conquista ou fracasso.

Nesse sentido, as barreiras que encontraram no ensino superior de natureza física, pedagógica, atitudinal e arquitetônica, foram enfrentadas pelo desejo pessoal de concluir a graduação, fato exposto pelo compromisso com as suas aprendizagens.

\section{Permanência}

O acesso aos conhecimentos sistêmicos da academia é fundamental para a permanência de estudantes com deficiência no ensino superior. Em Selau e Damiani (2013) no artigo intitulado "Fatores associados à conclusão da educação superior por 


\section{RevistAleph}

cegos", discute-se a possibilidade de permanência e de conclusão da educação superior por uma pessoa com cegueira.

Os autores trazem para discussão a inclusão a partir da utilização dos recursos tecnológicos e métodos específicos. Desse modo, afirmam que tais recursos não seriam suficientes para que os problemas relativos à participação desses estudantes no ensino superior fossem resolvidos. Discutir a possibilidade e permanência somente à luz de aparatos tecnológicos assistivos é como olhar para um iceberg apenas observando a parte que está fora d'água, ou seja, não se tem a visibilidade de todo. É preciso desconfigurar o olhar linear para compreender a natureza das coisas. Nesse escopo, Morin (2011) acena sobre a redução e disjunção. Aplicada às complexidades vivas e humanas, a lógica mecânica e determinista da máquina artificial pode também cegar e conduzir a excluir tudo aquilo que não seja quantificável e mensurável, eliminando dessa forma o elemento humano do humano.

O trabalho de Selau e Damiani (2013) faz inferência às escolhas relacionadas à permanência no ensino superior, as quais podem ocorrer sob influência do próprio ambiente ou fora dele. Isso se dá pelas relações que se estabelecem no convívio, sendo que nas relações em que o estudante se sente incluído e aceito as chances de permanência são aumentadas. Portanto, são necessárias ações de trabalho coletivo dentro desses espaços voltados para a inclusão desses acadêmicos.

Na pesquisa de Dantas (2012) no artigo intitulado "Rompendo a invisibilidade social com deficiência: a história de vida de uma universitária que exerce a autoadvocacia", a autora analisa a influência da autoadvocacia no desenvolvimento do papel sujeito de direito, colocando no campo de análise fatores para permanência no ensino superior. O resultado do estudo demonstra que a consciência do sujeito de direito perpassa um estado de consciência refletida no empoderamento, através do acesso aos conhecimentos sistematizados. Esse estado de consciência é percebido quando, por exemplo, o sujeito compreende seu direito ao acesso a uma escola com as adaptações necessárias, às melhorias no uso do espaço como direito de todo cidadão. Tal processo de luta e autoadvocacia reflete no desenvolvimento acadêmico, evidenciado na participação nos grupos de pesquisa e pela busca do benefício de bolsas 


\section{RevistAleph}

de estudos. No artigo de Selau (2015) "Genealogia da ideia de superação por cegos: um estudo com base em Vygotski", reitera-se que o ensino aos estudantes cegos, se corretamente planejado, pode levar a um processo compensatório que auxilia a superar as causas que geram (ou poderiam gerar) as derivações secundárias da deficiência.

No percurso de exclusão, relatado por uma estudante com cegueira nos estudos de Dantas (2012) no trabalho intitulado "Rompendo a invisibilidade social com deficiência: a história de vida de uma universitária que exerce a autoadvocacia", muitas vezes a deficiência era desconhecida pelos professores por não ser aparente. Nesses casos, a condição que os levaria a uma segregação passa desapercebida e, por conseguinte, as consequências também. Acerca desse caso nos lembramos a diferenciação que faz Goffman (1988) acerca dos desacreditados e desacreditáveis. Para Goffman (1988), uma pessoa é desacreditada quando sua desvantagem é aparente, percebida logo no contato visual, ao passo que a pessoa é desacreditável quando a diferença não está imediatamente aparente, não se tem dela um conhecimento prévio ou a pessoa não sabe que os outros a conhecem. Cotidianamente os estudantes com deficiência são expostos a situações de rompimento com barreiras a serem enfrentadas, nesse sentido precisam de amparo para que essa luta seja coletiva.

O envolvimento nos grupos de debate na causa das pessoas com deficiência é importante para a construção do pensamento emancipatório. O estudo de Dantas (2012) afirma que esse movimento coloca essas pessoas em contato com o universo de ferramentas necessárias para que se tornem autores de sua própria história, pelo poder de decisão sobre suas vidas. O movimento de autoadvocacia constitui, portanto, um caminho com possibilidades realísticas para romper com a história de exclusão das pessoas com deficiência nos contextos educacionais, assim como para reduzir as experiências de vulnerabilidade que sofrem. Há evidência nos estudos de que o percurso na escolarização básica, quando feito de acordo com o desenvolvimento de aprendizagem do estudante, torna-se significativo e leva a avanços na escolarização. Da mesma forma, a exclusão desses estudantes no processo de escolarização traz prejuízos sem precedentes. 


\section{RevistAleph}

O artigo em questão nos faz perceber que um dos grandes obstáculos ao desenvolvimento das pessoas com deficiência é das barreiras atitudinais. Lima e Tavares (2009) enfatizam que essas atitudes limitantes e constrangedoras estão presentes no ambiente escolar e são apresentadas na forma de estereótipos, ignorância, medo, rejeição, percepção de menos-valia, inferioridade, dentre outros.

$\mathrm{Na}$ exclusão ao acesso aos conhecimentos sistematizados desses estudantes, em todo percurso da escolarização, esses conhecimentos, muitas vezes, são negados ou tutelados. O entendimento de qualquer processo de aprendizagem parte da constatação de que o aluno sempre relaciona o que quer aprender com aquilo que já sabe. 0 processo de escolarização passa muitas vezes por responsabilizar o estudante pela aprendizagem e a chegada à universidade é atribuída ao estudante com mais veemência essa responsabilidade, ou seja, não se aceita que o processo de conhecimento seja repartido, interativo e de responsabilidade mútua do professor e do aluno.

O artigo de Gonçalves (2017) "Representações acerca dos projetos de vida de surdos universitários", traz a discussão sobre a relação no processo de escolarização e a falta de acessibilidade de modo que a ausência desta influência nas representações sociais e projetos de vida no contexto universitário. Esses fatores são imprescindíveis para o trajeto e permanência na universidade. Neste sentido, Glat e Blanco (2007, p. 16) apresentam fatores que devem ser observados pelas instituições de ensino, sendo eles "realimentar sua estrutura, organização, seu projeto político-pedagógico, seus recursos didáticos, metodologias e estratégias de ensino, bem como suas práticas avaliativas".

Sobre a permanência no ensino superior no artigo de Selau (2013) "Fatores associados à conclusão da educação superior por cegos: um estudo a partir de L.S. Vygotski" um estudo com estudantes egressos nos apontam a falta de preparo dos docentes na comunicação com esses estudantes, reflexo da carência de referencial teórico que apoiasse a inclusão de cegos. Tal fator foi um entrave na permanência e conclusão do curso de acadêmicos surdos. A presença de atendimento especializado é preponderante para que esse estudante tenha direito à participação efetiva na vida acadêmica 


\section{RevistAleph}

É necessário planejamento em prol das potencialidades e não das deficiências dos alunos e, para além disso, pensar na elaboração e efetivação de políticas de acessibilidade. Atualmente as instituições de ensino superior tem se articulado na implementação dos Núcleos de Acessibilidade. O Núcleo de Acessibilidade surge em decorrência de dois textos legais: a Política Nacional de Educação Especial na Perspectiva Inclusiva (BRASIL, 2008) e o Decreto n. 6.571, que disciplina sobre a estruturação dos Núcleos de Acessibilidade nas Instituições Federais de Ensino Superior(IFES), assim como suas funções no Art. 3으

O Ministério da Educação prestará apoio técnico e financeiro às seguintes ações voltadas à oferta do atendimento educacional especializado, entre outras que atendam aos objetivos previstos neste Decreto: [...] VI - estruturação de núcleos de acessibilidade nas instituições federais de educação superior. [...] § 3‥ Os núcleos de acessibilidade nas instituições federais de educação superior visam eliminar barreiras físicas, de comunicação e de informação que restringem a participação e o desenvolvimento acadêmico e social de alunos com deficiência (BRASIL, 2008).

Para o contexto de estudante com deficiência, primeiramente, é necessária a desconstrução do modelo médico patológico da deficiência reconhecido na literatura como nocivo ao processo de construção de autonomia.

Se o critério para afirmar a singularidade educativa desses sujeitos é o de uma caracterização excludente a partir da deficiência que possuem, então não se está falando de educação, mas de uma intervenção terapêutica; quando se acredita que a deficiência, por si mesma, em si mesma é o eixo que define e domina toda a vida pessoal e social dos sujeitos, então não se está construindo um verdadeiro processo educativo, mas um vulgar processo clínico. (SKLIAR 2013 p.7).

Na relação teoria e prática, é importante destacarmos o distanciamento vivido por esses estudantes diante dos discursos proclamados e a prática da inclusão. A integração é escancarada dentro das instituições, materializada através da separação dos estudantes na hora de fazer atividades. Nos estudos de Selau (2015) no artigo intitulado "Genealogia da ideia de superação por cegos: um estudo com base em Vygotsky" o autor suscita o trabalho pedagógico coletivo sob o ponto de vista da 


\section{RevistAleph}

defectologia de Vygotsky, na qual se diz que uma proposta pedagógica que esteja centrada em atividades individuais corre o sério risco de ser infrutífera.

Segundo Pieczkowski (2017) no artigo "Mediação Pedagógica na relação com Estudantes com Deficiência na Educação Superior" há uma visão romântica nesse processo e a inclusão é feita de forma genérica. Portanto, é necessária a inclusão desses estudantes na dimensão total dos acessos, não somente de integrá-los ao sistema educacional, o que perpassa a questão curricular. Ainda nesse artigo a autora problematiza a inércia das instituições em redimensionar seus currículos para que este público tenha lugar. Nas palavras de Skliar (2013) a neutralidade com que se assume o currículo foi um dos mecanismos mais nocivos quanto à limitação do acesso à informação e, sobretudo, em relação à identidade pessoal e cultural dos sujeitos.

\section{Acessibilidade e inclusão: lugar de fala}

Pontuamos o lugar de fala por considerarmos a tomada de consciência dos estudantes explícita nas pesquisas. A tomada de consciência, por alguns estudantes, foi fundamental para terem suas falas amplificadas e proferirem seus discursos denotando seus medos e angústias sobre a trajetória no ensino superior. Estas constatações oportunizaram a proposição de sugestões pelos próprios estudantes para a inclusão na universidade. O artigo de Selau e Damiani (2013) "Fatores associados à conclusão da educação superior por cegos: um estudo a partir de L.S. Vygotski", traz proposições que foram colocadas a respeito de: ingresso e permanência, posturas pedagógicas condizentes com a inclusão e a definição das universidades sobre políticas de acessibilidade. Esses fatores foram pontuados pelos estudantes por estarem fragilizados ainda na perspectiva da acessibilidade dentro do espaço acadêmico.

A tomada de consciência acontece muitas das vezes pelos estudantes tardiamente. O artigo de Gonçalves (2017) intitulado “Representações acerca dos projetos de vida de Surdos Universitários" diante das falas dos estudantes podemos perceber a fragmentação do percurso histórico da escolarização e como esse fator implica na representatividade desse estudante, influenciando em seu projeto de vida. 


\section{RevistAleph}

Portanto, é necessário desnaturalizar e tornar evidentes as situações de deficiência no grupo e na sociedade, observando e combatendo as barreiras que geram e fortalecem a deficiência (DINIZ, 2007).

De acordo com a dissertação de Septimio (2014), denota-se, por meio das falas dos estudantes, que a acessibilidade física não é um conceito universal, mas construído na relação sujeito-ambiente, concebida, sobretudo, como acesso para todos. Levando o conceito para campos gerais a acessibilidade, intrínseca na fala dos estudantes, não é comunal, mas reflete de experiências singulares e das necessidades pensadas na relação com o meio. Diante do exposto e relacionando deficiências e acessibilidade, o que se propõe acessível a um pode ser diferente para outros. A exemplo, no artigo de Gonçalves (2017) "Representação acerca dos projetos de vida de surdos universitários", o estudo nos diz, mediante a pesquisa feita com surdos, que a língua de sinais foi preponderante para o desenvolvimento da trajetória escolar e consequentemente ao ingresso ao ensino superior. Para esse grupo de estudantes a língua de sinais é item primordial para a inclusão e acesso aos espaços educacionais.

Já no artigo de Selau e Demani (2013) "Fatores Associados à conclusão da educação superior por cego", infere-se, mediante a pesquisa feita com cegos, que o sistema de leitura-escrita Braille, os programas computacionais leitores de tela e os gravadores de voz são os principais recursos de acessibilidade do cego na interação com o conteúdo científico. Nesse diálogo

Devemos considerar que a antonímia da diferença não é a igualdade, mas a singularidade constituída pelas identidades que, por serem múltiplas, quando se deparam umas diante as outras no âmbito de uma sociedade, demarcam as suas diferenças (CABRAL, 2018, p. 11).

Nesse sentido, o lugar de fala sobre acessibilidade não pode ser universal, mas relaciona-se à necessidade de cada um. Observamos nos estudos da ANPED que ainda há um fenômeno de busca pela "normalização", seja por parte dos professores, da gestão ou dos alunos. Também destacamos que alguns estudantes tendem a se colocar como responsáveis por sua superação aos obstáculos. Por outro lado, alguns textos analisados destacam esses estudantes como sujeitos de direitos e conscientes das 


\section{RevistAleph}

condições de acesso e inclusão necessárias para permanência nesses espaços enquanto ações não individuais, mas fruto de uma superação coletiva.

A ideia de tomada de consciência e da vontade dos sujeitos para a conclusão do ensino superior não pode ser tomada como razão para os docentes e instituições ficarem inertes. Toassa (2006) alerta que a tomada de consciência, para Vygotski, pressupõe uma relação de compreensão ou de conhecimento ativo, com respeito ao meio social, não apenas por percepção direta passiva. É preciso ancorar anseios e políticas institucionais em um lugar onde todos possam participar e usufruir.

No processo de inclusão é importante que se tragam as vozes, inquietudes e necessidades dos estudantes para o centro do debate, para que sejam representados. A partir do momento que a inserção desses estudantes for contemplada nas decisões, suas experiências serão tomadas como ponto de partida para os avanços na formulação de políticas de inclusão educacional.

\section{Considerações finais}

As observações descritas das publicações apontam na tentativa de entendermos como tem acontecido o processo de acesso e permanência desses estudantes no ensino superior. Conhecermos as múltiplas dimensões que formam o sujeito, seus desafios, e a que passo estamos sobre a inclusão no ensino superior é essencial nesse debate.

O resultado das produções científicas nos leva a localizar o sujeito em seu espaço geográfico, econômico e social, assim então, fazemos observações ao percurso de exclusão que perpassa o indivíduo, como uma intersecção de contextos que balizam o processo de exclusão educacional. Essa intersecção de contextos nos dizem de onde vem a tomada de consciência, para quem se tornou mais difícil, ou não, a caminhada no ensino superior, houve menção em todos os estudos analisados sobre o percurso no ensino básico. Portanto, a chegada desse estudante no nível de ensino superior, não há como ser dissociada do histórico educacional básico, uma vez que não diz sobre o construto da vida desse estudante, de onde representações sociais são advindas e 


\section{RevistAleph}

influenciam na vida acadêmica. As ações de políticas inclusivas no ensino superior devem ser pautadas nas narrativas dos estudantes com deficiência. As vozes científicas regionais, econômicas e sociais nos orientam a contextualizar o sujeito. Nesse sentido, as narrativas de um estudante com deficiência da região sul são diferentes de um estudante da região amazônica que é de onde emerge essa pesquisa.

Um efetivo processo de acesso e inclusão no ensino superior não é possível se não for considerado um processo inclusivo no ensino básico. Por entendermos que o nível de ensino é gradual, nesse sentido o acesso aos conhecimentos sistêmicos deve ser de direito em todo o processo educacional. Fica evidente na prática de acesso e permanência no ensino superior, não acompanhar os dispositivos legais vigentes.

Percebemos muitos desafios a serem superados nesse processo da efetivação da acessibilidade, reflexo disso são as poucas pesquisas sobre a temática nos textos da ANPED, ainda mais se considerarmos o fato de que todos os movimentos de visibilidade nesse nível são reflexo da movimentação das discussões de inclusão educacional que ocorrem nos centros de pesquisa do ensino superior.

Tal tema faz pensar na anulação desses estudantes nas discussões sobre políticas de acessibilidade e inclusão no contexto universitário. É preciso dar voz a esses estudantes sem a tutela histórica de acessos às discussões pertinentes. Esse conhecimento tutelado e negligenciado é refletido pelas raras publicações científicas

produzidas por pesquisadores com deficiência. Rodrigues (2004) lembra que a universidade não está pronta para atender a todos, precisando constituir-se em um espaço que privilegie discussões a respeito de práticas pedagógicas que favoreçam a consumação de uma política inclusiva dentro de seus muros.

Percebemos que os atrativos no ensino superior para os estudantes com deficiência têm sido o desejo pessoal de adentrar na graduação, favorecido pelas melhorias nas condições de acesso e permanência desenvolvidos nos últimos anos, os quais influenciam diretamente no número de matrículas nas instituições.

Faz-se necessário problematizar o percurso da educação de pessoas com deficiência. Portanto, problematizar a educação inclusiva em uma sociedade que reverbera exclusão nos convoca a subversão das estruturas sociais que ainda 


\section{RevistAleph}

maximizam as barreiras enfrentadas por esse público em Instituições de Ensino Superior- IES. Associações, políticos, expressões midiáticas da contemporaneidade, profissionais da educação e cada um de nós assumem um discurso pró-inclusão e, ao mesmo tempo, naturalizam as desigualdades ao esquecer que o projeto inclusivo é uma construção humana (LOPES e FABRIS, 2017).

Portanto o acesso e permanência nesses espaços por acadêmicos com deficiência devem ser planejados na condição humana, na perspectiva de ações colaborativas, no reconhecimento do outro em sua dimensão cultural e social. As instituições precisam se colocar no lugar de ouvintes desses estudantes, acolhendo as necessidades e minimizando as barreiras, para que o acesso e permanência sejam feitos de forma democrática.

\section{Referências}

BRASIL. Decreto no 6.949 de 25 de agosto de 2009. Diário Oficial da União. DF. Disponível em: http://www.planalto.gov.br/ccivil 03/ Ato2007-2010/2009/Decreto D6949.htm. Acesso em: 07 de mai. 2019

BRASIL. Lei no 13.146. Institui a Lei Brasileira de Inclusão da Pessoa com Deficiência (Estatuto da Pessoa com Deficiência). Disponível em: http://www.planalto.gov.br/ccivil 03/ ato20152018/2015/lei/l13146.htm\#: :text=LEI\%20N\% C2\%BA\%2013.146\%2C\%20DE\%206\%20DE\%20JULHO\%20DE\%202015.\&text=Institui\%20a\%20L ei\%20Brasileira\%20de,Estatuto\%20da\%20Pessoa\%20com\%20Defici\%C3\%AAncia). Acesso em: 04 de abr. 2020.

BRASIL. Lei no 13.409 a Lei no 12.711, de 29 de agosto de 2012, para dispor sobre reserva de vagas para pessoa com deficiência nos cursos técnico de nível médio e superior das instituições federais de ensino. Disponível em:

http://www.planalto.gov.br/ccivil 03/ ato2011-2014/2012/lei/l12711.htm. Acesso em: 29 de abr. 2020.

BRASIL. Estatuto da pessoa com deficiência. Disponível em: http://www.planalto.gov.br/ccivil 03/ ato2015-2018/2015/lei/l13146.htm. Acesso em 08 de maio. 2019

CABRAL, L.S.A. Políticas de ações Afirmativas, pessoas com deficiência e o reconhecimento das identidades e diferenças no ensino superior brasileiro. Rev. Arquivos Analíticos de Políticas Educativas, v. 26, n. 57, p. 11 abr. 2018. Disponível em: https:// https://epaa.asu.edu/ojs/article/view/3364. Acesso em 13 de jun. 2020. 


\section{RevistAleph}

DANTAS, Taísa. Rompendo a invisibilidade social de pessoas com deficiência: a história de vida de uma universitária que exerce a autoadvocacia. 2012. Disponível em: http://www.anped.org.br/. Acesso em: 30 de mai. 2020.

DINIZ, Débora. O que é deficiência. São Paulo: Brasiliense, 2012.

GOFFMAN, Erving. Estigma: notas sobre a manipulação da identidade deteriorada. 4a ed. Rio de Janeiro: LTC, 1988.

GLAT, R., BLANCO, L. Educação Especial no contexto de uma Educação Inclusiva. In: GLAT, Rosana. Educação Inclusiva: cultura e cotidiano escolar. Rio de Janeiro: Sete Letras, p. 15-35, 2007

GONÇALVES, Arlete. Representações acerca dos projetos de vida de surdos universitários. 2017. Disponível em: http://www.anped.org.br/. Acesso em: 30 de mai. 2020.

LOPES, Maura Corcini; FABRIS, Eli Henn. Inclusão \& educação. Belo Horizonte: Autêntica Editora, 2017.

MORIN, Edgar. Os setes saberes necessários à educação do futuro. São Paulo: Cortez, 2011.

PIECZKOWSKI, Tania. Mediação pedagógica na relação com estudantes com deficiência na educação superior. 2017. Disponível em: http://www.anped.org.br/. Acesso em: 30 de mai. 2020.

RODRIGUES, David. Inclusão e Educação: doze olhares sobre a educação inclusiva. São Paulo: Summus, 2006.

SASSAKI, Romeu Kazumi. Inclusão: construindo uma sociedade para todos. Rio de Janeiro: WVA, 2006.

SILVA, L.M. O estranhamento causado pela deficiência: preconceito e experiência. In: Revista Brasileira de Educação, v.11, n. 33 (set/dez). Campinas, São Paulo: Autores Associados, 2006, pp. 424-434.

SELAU, Bento; DAMIANI, Magda. Fatores associados à conclusão da educação superior por cegos: um estudo a partir de L. S. Vygotski. 2013. Disponível em:

http://www.anped.org.br/. Acesso em: 30 de mai. 2020.

SELAU, Bento. Genealogia da ideia de superação por cegos: um estudo com base em Vygotski. 2015. Disponível em: http://www.anped.org.br. Acesso em: 30 de mai. 2020.

SEPTIMIO, Carolline. Acessibilidade física e inclusão no ensino superior: um estudo de caso na Universidade Federal do Pará. 2014. Dissertação (Mestrado em Educação) - Universidade Federal do Pará, Belém, 2014.

SKLIAR, Carlos. Educação \& Exclusão: abordagens socioantropológicas em educação especial. 7.ed. Porto Alegre: Mediação, 2013. 


\section{RevistAleph}

TRIVINÕS, Augusto. N.S. Introdução à pesquisa em ciências sociais. Editora: Atlas, 2011.

THESING, Mariana; COSTAS, Fabiane. Estado do conhecimento e educação especial: um olhar para as produções da Anped (2010 a 2015). 2017. Disponível em: http://www.anped.org.br/. Acesso em: 30 de mai. 2020.

TOASSA, G. Conceito de consciência em Vygotsky. Psicologia USP, São Paulo, v.17, n.2 p.5983,2006

Data do envio: $26 / 08 / 2020$

Data do aceite: $20 / 11 / 2020$. 